\title{
Dendrimer-based strategies for cancer therapy: Recent advances and future perspectives
}

\author{
Zhijuan Xiong, Mingwu Shen and Xiangyang Shi
}

\begin{abstract}
This review reports some recent advances on the use of dendrimer-based systems for cancer therapy. Dendrimers are emerging as promising carriers or stabilizers for drugs and nanoparticles (NPs) due to their highly branched 3dimensional globular shape, internal hydrophobic cavity and multiple peripheral functional groups. The fabricated nanoplatforms loaded with therapeutic agents such as drugs, siRNAs or NPs can be further modified to have targeting specificity, antifouling properties and good biocompatibility. In particular, recent advances in the surface modifications of dendrimers and the application of dendrimers as versatile platforms for different therapeutic treatments to cancer including chemotherapy, radiotherapy, photothermal therapy, photodynamic therapy, gene therapy, and combination therapy will be introduced in detail.
\end{abstract}

Keywords: dendrimer-based systems, cancer therapy, drug, nanoparticles, therapeutic agents

\section{INTRODUCTION}

Dendrimers with "onion skin-like" branched layers and a precise number of functional groups can act as a monodispersed platform for various biomedical applications. The word "dendrimer" originated from the Greek word "dendrons" with the literal meaning of tree or branches [1]. Typically starting from a core, the dendrimer grows to have emanated branches step by step to form different generations, having particular size, terminal functional group and defined molecular weight. The most major ways to synthesize dendrimers are the divergent method and convergent growth, which was developed by Tomalia [2], and Hawker and Frechet [3], respectively. Of course, some less well-explored strategies have also been in- troduced by other researchers, such as double exponential growth [4], hypercore and branched monomer growth [5], click chemistry [6] and lego chemistry [7].

Owing to its special 3-dimensional (3D) structure, perfect water solubility, low immunogenicity and easiness of functionalization, the dendrimer-based system has become one of the most promising and efficient platforms for cancer therapy [8]. Since the first ever dendrimers were described by Vögtle in 1978, a variety of different dendrimer types have been developed and used, such as poly(amidoamine) (PAMAM) dendrimer [9-13], poly (prophylenimine) (PPI) dendrimer [14,15], polylysine (PLL) dendrimer [16] and phosphorus dendrimer [17], providing versatile dendrimer-based systems for cancer treatment.

PAMAM dendrimers with ethylenediamine core and branch cell multiplicity are usually synthesized by the "divergent" method (Fig. 1). They are the first complete dendrimer family to be synthesized, characterized and commercialized $[2,18]$ and often referred to as "artificial proteins" (Fig. 2) [8]. These outstanding features afford their wide uses as globular protein replacements for different applications. PPI dendrimers were firstly reported by Buhleier et al. [19] in 1978. They usually have a core of 1,4-diaminobutane and are synthesized with a divergent method (Fig. 3) [20,21]. PLL dendrimers containing Llysine in their branching units are one kind of peptidebased dendrimers [22,23]. Phosphorous dendrimers with phosphorus atoms at each branching unit [24,25] are considered to be particularly suitable for biomedical applications due to the phosphorus element, which is essential for life $[7,26]$.

The unique characteristics of dendrimers distinguish

State Key Laboratory for Modification of Chemical Fibers and Polymer Materials, College of Chemistry, Chemical Engineering and Biotechnology, Donghua University, Shanghai 201620, China

* Corresponding author (email: xshi@dhu.edu.cn) 


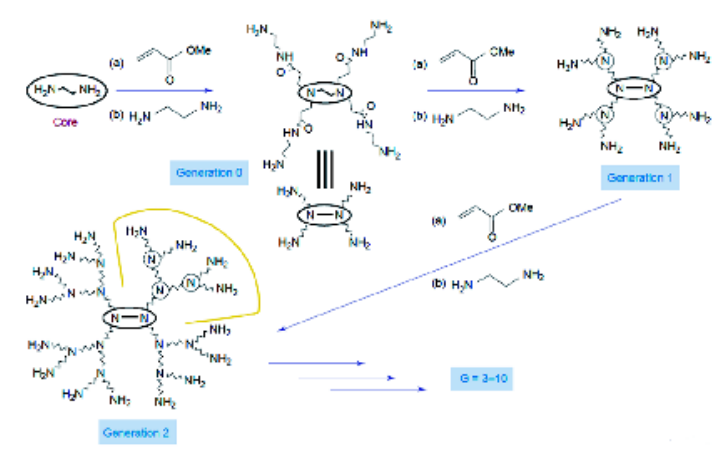

Figure 1 Synthesis of tetra-functional poly(amidoamine) (PAMAM) dendrimers: exhaustive Michael addition of amine groups with methyl acrylate, followed by amidation of the resulting esters with ethylenediamine. Reproduced with permission from Ref. [8], Copyright 2001, Elsevier.

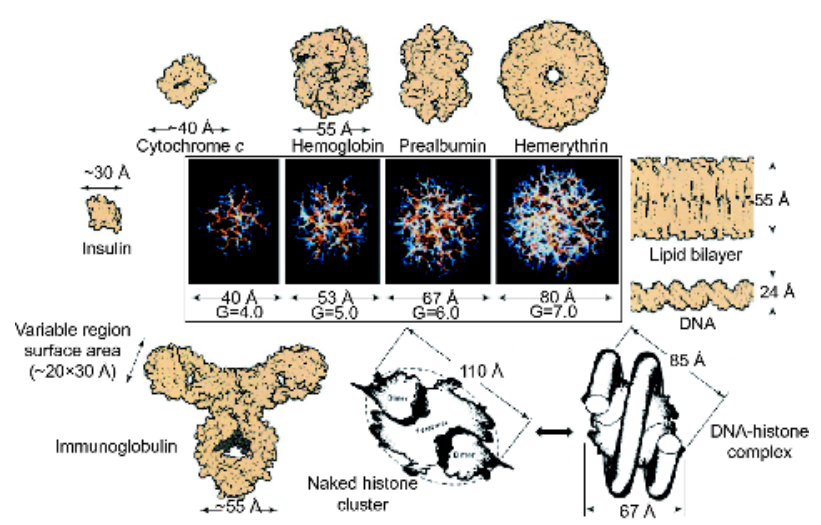

Figure 2 A dimensionally scaled comparison of a series of poly(amidoamine) (PAMAM) dendrimers $\left(\mathrm{NH}_{3}\right.$ core; $\left.\mathrm{G}=4-7\right)$ with a variety of proteins, a typical lipid-bilayer membrane and DNA, indicating the closely matched size and contours of important proteins and bioassemblies. Reproduced with permission from Ref. [8]. Copyright 2001, Elsevier.

them from conventional linear polymers [27-29] and endow dendrimers with advantages for many delivery applications [30]. The globular shape and the defined periphery functional groups of dendrimers endow them with an ability to not only encapsulate drug molecules within their interior or conjugate drug molecules on their periphery, but also be modified with a range of functional agents. The globular shape of dendrimers, as opposed to the random coil-structured linear polymers, could affect their biological properties and thus lead to the discovery of many interesting effects [31]. Studies have shown that PAMAM dendrimer-based drug delivery system has lower half-maximal inhibitory concentration $\left(\mathrm{IC}_{50}\right)$ of drugs and more cellular uptake than linear PEG-based

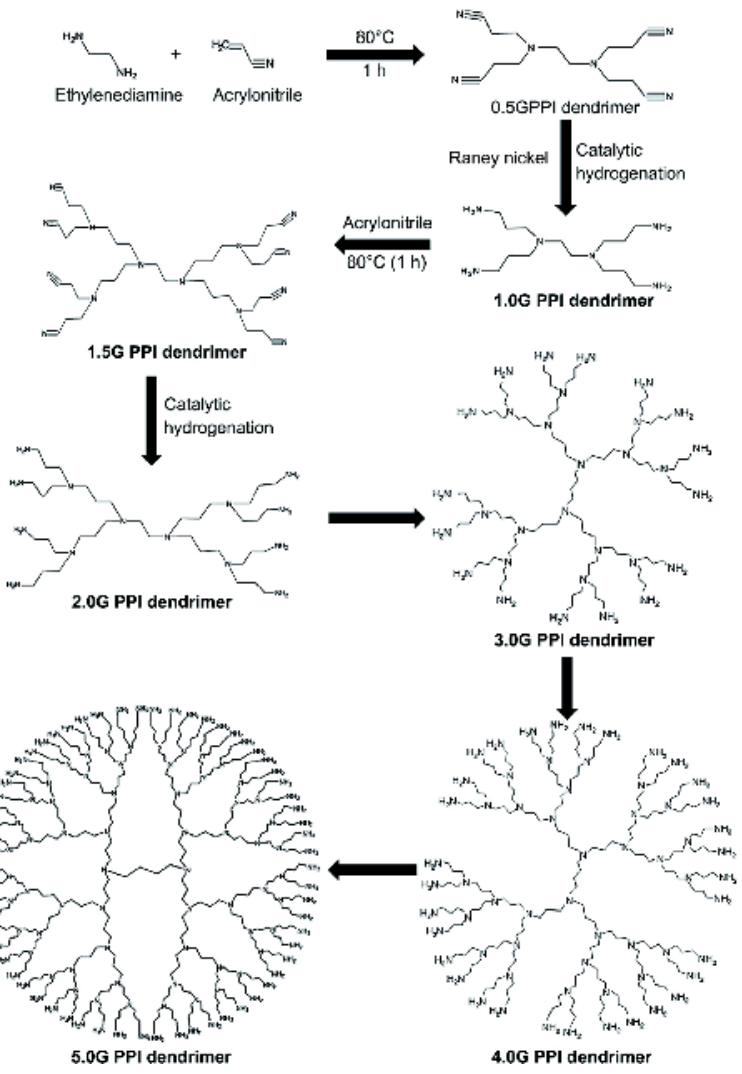

Figure 3 Synthesis of different generations (3.0G, 4.0G and 5.0G) of PPI dendrimers. Reproduced with permission from Ref. [21]. Copyright 2014, Elsevier.

system [32]. Due to the great monodispersity that is close to that of protein and the controlled architecture, nanosize, and shape, dendrimers are often considered to be one of the most promising vehicles for the delivery of drugs, proteins, and other therapeutic agents [27,33-35].

For desired biomedical applications, surface modification of dendrimers is necessary. For instance, PEGylation endows the system with good biocompatibility, stability and elongated blood circulation time. For nanomedicinal applications, dendrimers have been used as platforms to physically load drugs by electrostatic interaction or by hydrophobic interaction, covalently link drug molecules on the dendrimer periphery, compress genetic materials (e.g., short-interfering RNA, siRNA) via electrostatic interaction, entrap inorganic NPs within the dendrimer interior, or stabilize inorganic NPs. These strategies allow for the generation of various dendrimer-based nanoplatforms for different treatments of cancer including chemotherapy, radiotherapy, photothermal therapy (PTT), photodynamic therapy (PDT), gene therapy, or 
combination therapy. Since some of the related research in the field has been reviewed earlier [36-38], in this review, we mainly report the recent advances (from 2013 till now) in the applications of different dendrimer-based strategies for cancer therapy. This review starts with a brief introduction, followed by detailed discussion of the related research in the field, and ends with conclusion and future perspectives. It should be noted that this review does not intend to give a comprehensive overview of the whole literature database, but rather discusses some key developments and advances in the field in the last several years.

\section{DENDRIMER SURFACE DECORATION AND FUNCTIONALIZATION}

The toxicity of dendrimers impedes their biological applications due to the characteristics, which is related to the chemistry of the core and mainly to the surface end groups [39]. Amine-terminated dendrimers have high positive charge that strongly interacts with negatively charged cell membranes to result in cell lysis [40]. Therefore, the surface decoration of dendrimers is necessary (Table 1). In addition, the properties of nonspecific cell membrane binding and specific targeting can also be gained through surface functionalization.

\section{PEGylation}

Polyethylene glycol (PEG) modification is the dominating way to increase the biocompatibility of dendrimers, to prolong the blood circulation time of dendrimers in vivo and to enable tumor accumulation through the enhanced permeability and retention (EPR) effect [41]. In a previous report, Peng et al. [42] reported that generation 5 (G5) PAMAM dendrimers with PEG modification had enlarged surface periphery, enabling enhanced entrapment of Au NPs to form stable dendrimer-entrapped gold nanoparticles (Au DENPs) after acetylation of the remaining dendrimer terminal amines. The PEGylated Au DENPs have improved cytocompatibility, longer halfdecay time $(31.76 \mathrm{~h})$ than that of Au nanorods (12.5 h). Furthermore, PEG is also commonly used as a spacer between dendrimers and targeting or other functional agents. For instance, Shrikant et al. [43] studied the influence of PEG spacer chain length on the targeting efficiency of folate (FA)-modified PPI dendrimers. In that work, PEG with different $M_{\mathrm{w}}(1,000,4,000,6,000$, or 7,500 ) was used to connect FA and PPI, followed by docetaxel loading. The results show that PPI modified with PEG $\left(M_{\mathrm{w}}=7,500\right)$ has lowest drug release rate and all the PEGylated PPI dendrimers have better blood compatibility than PPI dendrimers without PEGylation. Due

Table 1 Examples of dendrimer surface decoration and functionalization

\begin{tabular}{|c|c|c|c|}
\hline Dendrimer type & Surface modification agent & Function & Reference \\
\hline \multirow[t]{10}{*}{ PAMAM } & PEG & Reducing cytotoxicity & {$[42]$} \\
\hline & Phosphorylcholine & & {$[44]$} \\
\hline & CBAA & & {$[45,46]$} \\
\hline & Acetyl & & {$[42,46-48]$} \\
\hline & CBAA & & {$[45,46]$} \\
\hline & RGD & & [49-53] \\
\hline & pAb antibody & & [54] \\
\hline & Lactobionic acid & & [55] \\
\hline & Fluorescein isothiocyanate & Fluorescence imaging & [55] \\
\hline & Fluorochrome Cy5.5 & & [50] \\
\hline \multirow[t]{5}{*}{ PPI } & PEG & Reducing cytotoxicity & {$[43,56]$} \\
\hline & Maltotriose & & [57-59] \\
\hline & Anti-EGFRvlll scFV & Targeting property & {$[60]$} \\
\hline & FA & & {$[61]$} \\
\hline & Histidine, pyridine, piperazine & Buffering capacity property & {$[62]$} \\
\hline \multirow[t]{2}{*}{ PLL } & PEG & Reducing cytotoxicity & [63] \\
\hline & FA & Targeting property & {$[64]$} \\
\hline \multirow[t]{2}{*}{ Phosphorous dendrimers } & Azabisphosphonate & Targeting property & [65] \\
\hline & 8-Anilino-1-naphthalenesulfonate & Fluorescence imaging & [66] \\
\hline
\end{tabular}


to the optimized steric hindrances of PEGs with $M_{\mathrm{w}}$ of 4,000 , the designed multifunctional PPI device enables the highest cellular uptake, which is desired for drug delivery applications.

\section{Zwitterion modification}

In general, NPs suffer quick clearance by reticuloendothelial system (RES) within organs, such as the liver, spleen, and lung after intravenous injection [67-69]. For highly efficient cancer therapy, it is critical to make the drugs effectively delivered to the tumor region. Hence, it is important to design a drug delivery system having good antifouling properties (protein resistance ability), extended blood circulation time, and limited macrophage cellular uptake by the RES. Studies have shown that NPs modified with zwitterionic molecules of cysteine display good antifouling properties, extended blood circulation time and enhanced tumor penetration and retention [70,71]. The special structure of zwitterionic molecules consists of an equal molar ratio of positive and negative charges in close proximity. Each ion pair of positive and negative groups can hold a large quantity of water molecules around and form a protective layer of water on the surface of materials, thus shielding the hydrophobic interactions between the pollutants and the material surface [46]. Jia et al. [44] used acryloyloxyethyl phosphorylcholine (APC) to modify G5 PAMAM dendrimers and about 50 APCs were connected to each G5 PAMAM dendrimer as confirmed by ${ }^{1} \mathrm{H}$ NMR and potentiometric titration. The results showed that the zwitterionic "lipid-like" molecules can reduce the cytotoxicity of dendrimers but at the same time retain their cell uptake ability. Wang et al. [45] reported the modification of carboxybetaine acrylamide (CBAA) onto G5 PAMAM dendrimers. The CBAA-modified dendrimers showed excellent compatibility with protein and cells, and in particular, the CBAA-modified dendrimers could exist and keep their conformation in the presence of fibrinogen in aqueous solution and the hydrodynamic size of the dendrimers did not change, confirming their excellent antifouling properties. Recently, our group [46] used G5 PAMAM dendrimer modified with different degrees of CBAA as templates to entrap Au NPs. Compared with the control group $\left\{\left(\mathrm{Au}^{0}\right)_{100}-\mathrm{G} 5 \cdot \mathrm{NHAc}-m \mathrm{PEG}_{20}\right\}$, the CBAAmodified one showed better antifouling properties and higher degree of CBAA modification resulting in much less macrophage cellular uptake, longer half-delay time $(44.54 \mathrm{~h})$, and enhanced computed tomography (CT) imaging of rat blood pool, rabbit lymph nodes and mouse tumors after intravenous injection.

\section{Glycosylation}

The decoration of carbohydrate ligands to dendrimers renders them with nearly neutral charges [35], improved biocompatibility in vitro and in vivo [49], which hence may be used to substitute PEGylation to achieve the same goals [72,73]. The most commonly utilized carbohydrate ligands include glucose, maltose, maltotriose, mannose and lactose, meanwhile the intermediate enamine of dendrimers can be reduced to form secondary and tertiary amines bearing the desired carbohydrate units [74]. The glycosylated dendrimers are widely applied as drug delivery systems, therapeutics and diagnostics for neurodegenerative diseases. Ida et al. [57] studied the maltotriose residue-modified PPI dendrimers with DNAdamaging agent fludarabine for chronic lymphocytic leukemia therapy. The addition of PPI-G4-OS-Mal-III and PPI-G4-DS-Mal-III dendrimers to B-CLL cells significantly induced the cell apoptosis within these lymphocytes. Moreover the glycosylated PPI dendrimers can even be used as antiamyloidogenic and antiprionic agents. Klementieva et al. [58] found that PPI glycodendrimers of the fourth and fifth generations with neutrally charged maltose shell can reduce the toxicity of the brain extracts of Alzheimer's disease to SH-SY5Y cells, a neuroblastoma cell line. The neutrally charged or cationic maltose shellmodified PPI dendrimers were able to penetrate the cytoplasm of cells and reach the brain when administered intranasally. Besides reducing the cytotoxicity and endowing the dendrimers with the ability to cross the blood brain barrier, glycosylation can also be used to improve the $r_{1}$ relaxivity of dendrimers-based magnetic resonance (MR) imaging contrast agents. The PPI-MAL DS-DOTA (Gd) complexes with an $\mathrm{r}_{1}$ relaxivity of $10.2 \mathrm{mmol}^{-1} \mathrm{~L} \mathrm{~s}^{-1}$ much higher than that of commercial DTPA(Gd) agent (3.4 $\mathrm{mmol}^{-1} \mathrm{~L} \mathrm{~s}^{-1}$ ) enabled enhanced MR imaging of mouse blood pool and organs. The modification of maltose leads to a longer global rotational correlation time due to the increased molecular dimension of the dendrimers/Gd (III) complexes, and a longer exchange lifetime of the coordinated water molecules resulting from H-bond between hydroxy of maltose and other ligand units [59].

\section{Targeting agent modification}

Although dendrimers can passively target tumor tissues by EPR effect due to the hyper permeability of tumor vasculature $[75,76]$, the low specificity-resulted dose-dependent side effects still impede the biological applications of dendrimers. Fortunately, periphery groups of dendrimers enabled covalent conjugation of various tar- 
geting moieties including monoclonal antibodies, peptides/proteins, vitamins, glycosylation, or other ligands for active targeting of cancer cells via a receptor-mediated pathway $[55,60,62,65,77-79]$. Here we introduce several typical targeting agents such as Arg-Gly-Asp (RGD) peptide, FA and anti-human myoglobin detection antibody (pAb) for dendrimer surface modifications. RGD, a tripeptide, has a high affinity to cancer cells overexpressing $\alpha_{v} \beta_{3}$ integrins. The RGD peptide is usually conjugated with PEG through amide bond or thiol-maleimide coupling, followed by reacting the other PEG carboxyl end group with the terminal amine of dendrimers [49,50]. For instance, our group used RGD to modify PAMAM dendrimers of different generations for gene and drug delivery, as well as PTT of tumors [51-53]. FA can specially connect with FA receptors, which are overexpressed in many types of human carcinomas [80,81]. Kesharwani et al. [61] investigated the potential to use FA-anchored and drug melphalan-loaded PPI dendrimers with different generations (PPI3, PPI4 and PPI5) for targeted therapy of cancer cells. The authors showed that $\mathrm{IC}_{50}$ values of MP-FPPI3, MP-FPPI4, MPFPPI5, and free melphalan were $8 \pm 0.15,0.9 \pm 0.02,0.2$ \pm 0.01 and $10 \pm 0.17 \mu \mathrm{mol} \mathrm{L}{ }^{-1}$, respectively for MCF-7 cells (a human breast cancer cell line), while for CASKI cells (a human uterine cancer cell line), the corresponding IC50 values were $3.11 \pm 0.04,0.93 \pm 0.06,0.75 \pm 0.02$ and $2.17 \pm$ $0.11 \mu \mathrm{mol} \mathrm{L}{ }^{-1}$, respectively. Hence, the FA-mediated targeting efficacy showed a generation-dependent behavior with a higher cancer cell targeting efficiency for higher generation dendrimers. In another work, Zhang et al. [54] reported the bioconjugation of gold nanoparticle (AuNP)-PAMAM with pAb antibody by mixing the NPs and antibody followed by centrifugation to move the excess antibodies. The electrochemical characteristics of the immunosensor assay indicated that pAb-AuNP-PAMAM could be specifically adsorbed to mAb-modified glassy carbon electrode in the presence of target myoglobin, exhibiting high specificity and good precision toward target myoglobin.

\section{Others}

Apart from the four types of decoration and functionalization discussed above, lots of other modification strategies have been performed to endow the dendrimers with good biocompatibility and desired functionality [62]. Zhang et al. [48] investigated the influence of different functional groups on the release of anticancer drug doxorubicin (DOX) from PAMAM dendrimers. The terminal amines of G5 PAMAM dendrimers were firstly converted to acetyl (G5.NHAc), glycidol hydroxyl (G5. $\mathrm{NGlyOH}$ ), and succinamic acid (G5.SAH), respectively, followed by physical encapsulation of DOX. The NMR results showed that interactions between G5.NHAc or G5.NGlyOH dendrimers with DOX were much stronger than that between G5.SAH dendrimers and DOX, hence DOX released quickly from the G5.SAH dendrimers. In addition, acetylation is a widely used way to reduce the cytotoxicity of dendrimers to neutralize the dendrimer terminal amines, which is proven to be toxic to cells at a relatively high concentration [64]. At the dendrimer concentration above $1 \mathrm{mmol} \mathrm{L}^{-1}$, the fully acetylated generations 2 and 4 PAMAM dendrimers were nontoxic, while the cell viability for $50 \%$ acetylated PAMAM dendrimer was $70 \%$ at $1 \mathrm{mmol} \mathrm{L}^{-1}$ for Caco-2 cells [47]. Interestingly, $50 \%$ acetylation of dendrimers endowed them with the highest permeability coefficient of $3.0 \times 10^{-6} \mathrm{~cm} \mathrm{~s}^{-1}$, but the fully acetylated dendrimers and the unmodified dendrimers had almost the same membrane permeability $\left(2.1 \times 10^{-6}\right.$ versus $\left.1.7 \times 10^{-6} \mathrm{~cm} \mathrm{~s}^{-1}\right)$. Furthermore the dendrimer peripheral groups can be modified with other functional agents such as DOTA or dye for imaging element chelating or for fluorescence imaging $[50,66,82,83]$. For example, the dendrimerDOTA [59] can be used for chelating agent such Gd (III) ions for MR imaging, and dendrimer-FITC conjugates [46] are usually applied in cellular tracking of the materials in vitro or fluorescence imaging in vivo.

\section{CANCER THERAPY}

With the unique structural characteristics, globular shape, and abundant terminal groups $[84,85]$, dendrimers have been widely used for drug delivery [36], as well as for the development of various nanoplatforms for different types of cancer therapy such as chemotherapy, radiotherapy, PTT, PDT, gene therapy and the combination therapy (Table 2).

\section{Dendrimer-based drug delivery systems}

The dendrimer-based platform can be used to load anticancer drugs either through physical encapsulation or through covalent conjugation. According to the combination form of dendrimers and drugs (Fig. 4), the dendrimer-based drug delivery system can be divided into two main types: (1) dendrimer/drug complexes and (2) dendrimer/drug conjugates.

\section{Dendrimer/drug complexes}

Diverse drugs can be encapsulated within the hydrophobic interior of dendrimers or connected to the den- 
Table 2 Examples of dendrimer-based cancer therapy

\begin{tabular}{|c|c|c|c|}
\hline Cancer therapy type & Dendrimer type & Founctional agents & Reference \\
\hline \multirow[t]{6}{*}{ Chemotherapy } & PAMAM & DOX & [86] \\
\hline & & 2-ME & [87] \\
\hline & & GEM & [88] \\
\hline & & $\alpha$-TOS & {$[53,89]$} \\
\hline & PPI & DOX & [90] \\
\hline & PLL & MTX & {$[43]$} \\
\hline \multirow[t]{2}{*}{ Radiotherapy } & PAMAM & ${ }^{131} \mathrm{I}$ & {$[91,92]$} \\
\hline & & ${ }^{177} \mathrm{Lu}$ & {$[93,94]$} \\
\hline \multirow[t]{5}{*}{ PTT } & PAMAM & GNRs & [95] \\
\hline & & ICG & [96] \\
\hline & & $\mathrm{MoS}_{2}$ & [97] \\
\hline & & $\mathrm{CuS}$ & [98] \\
\hline & & Au NSs & [51] \\
\hline \multirow[t]{4}{*}{ PDT } & PAMAM & Ce6 & [99] \\
\hline & PPI & Phthalocyanines & {$[100]$} \\
\hline & Phocnhorue dendrimere & Methylene blue & {$[101]$} \\
\hline & Pnospnorus denarmers & Rose bengal & {$[101,102]$} \\
\hline \multirow[t]{7}{*}{ Gene therapy } & PAMAM & Luciferase-targeted siRNA or Bcl-2 siRNA & {$[103]$} \\
\hline & & Bcl-2 siRNA & {$[51,97,104-107]$} \\
\hline & & $\begin{array}{l}\text { siBcl-xl, siBcl-2, siMcl-1 siRNAs and a } \\
\text { siScrambled sequence }\end{array}$ & {$[108]$} \\
\hline & PPI & Bcl-2 siRNA & [109] \\
\hline & & Luciferase-targeted siRNA & {$[60]$} \\
\hline & & pDNA & {$[56,62]$} \\
\hline & Phosphorus dendrimers & $\begin{array}{l}\text { siBcl-xl, siBcl-2, siMcl-1 siRNAs and a } \\
\text { siScrambled sequence }\end{array}$ & {$[108]$} \\
\hline
\end{tabular}

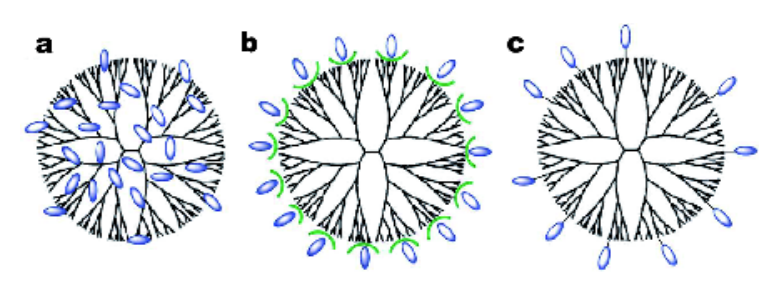

Figure 4 Dendrimer-based drug delivery systems of different types: (a) Drugs physically entrapped inside the dendrimers; (b) drugs adsorbed on the surface of the dendrimers through different intermolecular interaction forces; (c) drugs conjugated to the dendrimers. Reproduced with permission from Ref. [37]. Copyright 2013, the Royal Society of Chemistry.

drimer surface through hydrogen bonding, van der Waals interactions, and electrostatic interactions [110]. The formation of dendrimer/drug complexes not only increases the solubility of hydrophobic anticancer drug, but also renders the drug to be released in a sustained manner. In this case, the molecular structure of drugs has not been changed, and hence the therapeutic activity of the drugs is well maintained. A range of hydrophobic anticancer drugs such as DOX, 2-methoxyestradiol (2-ME) and methotrexate (MTX) have been physically complexed with dendrimers. In our earlier work, we showed that the surface functional groups of G5 PAMAM dendrimers significantly influenced the therapeutic activity of 2-ME after it was encapsulated within the dendrimers. 2-ME encapsulated within G5 dendrimers with succinamic acid termini did not exhibit anticancer activity to KB cells (a human epithelial carcinoma cell line), while once encapsulated within G5 dendrimers functionalized with glycidol hydroxyl and acetamide groups, the complexes were able to deliver 2-ME to inhibit cancer cell growth [87]. In another study, generation 4 PPI-grafted nanocrystalline cellulose (NCC) was modified with FA to load DOX and the DOX release under different $\mathrm{pHs}$ was tested. At $\mathrm{pH} 7.4$ and $\mathrm{pH} 5.3$, the NCC without FA showed a higher cumulative DOX release when compared to the FA-conjugated systems, primarily due to the steric hindrance of the conjugated FA. Meanwhile under a lower 
$\mathrm{pH}$, the DOX release rate from both FA-targeted NCC and non-targeted NCC increased [90].

\section{Dendrimer/drug conjugates}

Dendrimer/drug conjugates are formed through covalent conjugation of chemotherapeutic drugs with the dendrimer periphery via covalent bond. The drug should be released after the spacer between dendrimers and drugs are broken up. Therefore, the drug release kinetics is generally related to the types of the connecting bond. The most used linkers include hydrazone, imine, ester, carbamate, amide, disulfide, and enzyme-cleavable peptide sequence $[111,112]$. For instance, DOX was conjugated to the G4 PAMAM dendrimers through an acid-labile-hydrazone linkage, which is endo/lysosomal $\mathrm{pH}$-sensitive [86]. The in vitro drug release measurement showed that $11.5 \%$ of DOX was released after $60 \mathrm{~h}$ incubation at $\mathrm{pH}$ 7.4 , and $67.6 \%$ and $88.2 \%$ drug released within 25 and $60 \mathrm{~h}$, respectively at $\mathrm{pH}$ 5.0. Zhang et al. [88] showed that the glycyl phenylalanyl leucyl glycine tetra-peptide, an enzyme-cleavable linker, could be used to conjugate gemcitabine (GEM) and lysine peptide dendrimer. Owing to the presence of Cathepsin B enzyme in tumor cellular environments, GEM was quickly released from the particles. In vivo assay data demonstrated that PEGylated lysine peptide dendrimer-GEM conjugates could inhibit the tumor growth (90\%) 2-fold better than free GEM.

\section{Chemotherapy}

Chemotherapy of cancer is based on the use of chemical drugs to prevent the proliferation, invasion and metastasis of cancer cells. Generally cancer chemotherapy faces lots of challenges including low specificity resulting in dose-dependent side effects, short blood circulation time and high drug tolerance $[41,113]$. While the dendrimer/ drug complexes or conjugates can overcome these defects well: 1) the multiple modification of terminal agent of dendrimers can endow them with targeting specificity to cancer cells; 2) the special dendritic platform efficiently retards the release rate of drugs and elongates the blood circulation time to have improved pharmacokinetics; 3 ) the introduction of particular drugs or agents can restrain the drug tolerance [114]. Previously, Zhu et al. [53] reported a way to covalently connect dendrimer and $\alpha$ tocopheryl succinate ( $\alpha$-TOS), which could kill cancer cells even when combined with dendrimers. The formed $\mathrm{Au}$-TOS-RGD DENPs or Au-TOS-FA DENPs were used for targeted chemotherapy and computed tomography (CT) imaging of cancer cells. For Au-TOS-RGD DENPs, the $\mathrm{IC}_{50}$ of $\alpha$-TOS was $18.2 \mu \mathrm{mol} \mathrm{L}{ }^{-1}$, which is much lower
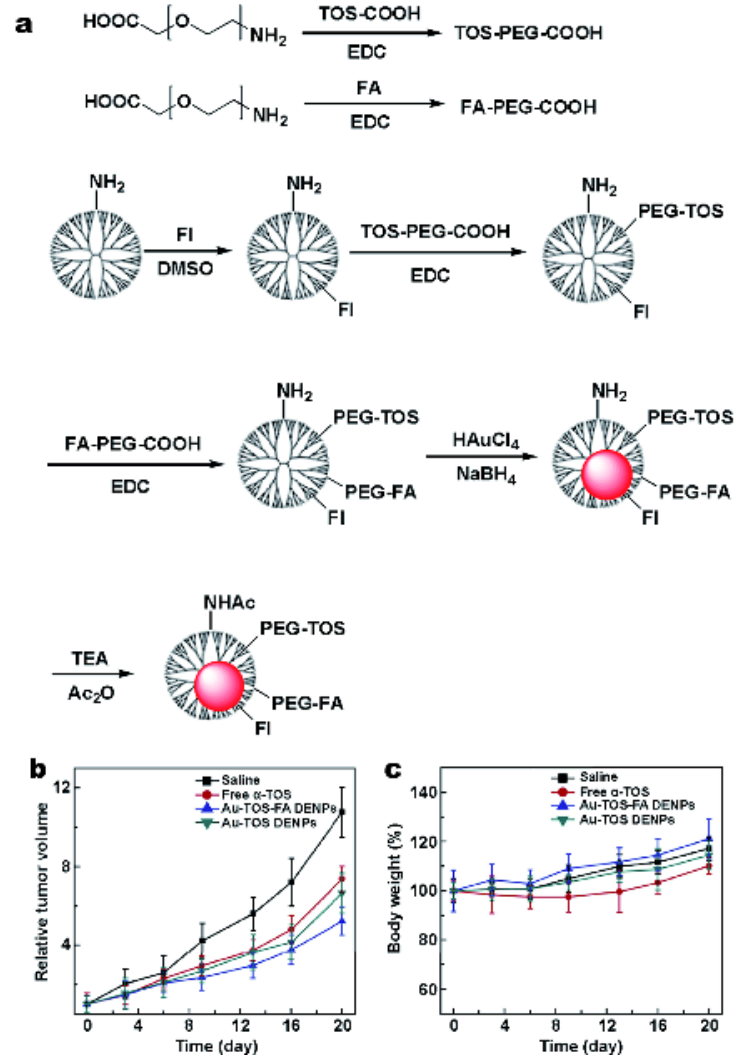

Figure 5 Schematic illustration of the synthesis of the Au-TOS-FA DENPs (a), growth of U87MG xenografted tumors after various treatments (b) and the body weight of U87MG tumor-bearing mice after various treatments (c). The relative tumor volumes and body weight were normalized according to their initial weights (Mean \pm SD, $n=6$ ). Reproduced with permission from Ref. [89]. Copyright 2015, Elsevier.

than that of free $\alpha$-TOS $\left(33.8 \mu \mathrm{mol} \mathrm{L} \mathrm{L}^{-1}\right)$ for treatment of U87MG cells (a human glioblastoma cancer cell line). As for Au-TOS-FA DENPs (Fig. 5), the $\mathrm{IC}_{50}$ of $\alpha$-TOS was $19.2 \mu \mathrm{mol} \mathrm{L}{ }^{-1}$, slightly higher than that of Au-TOS-RGD DENPs [89], presumably resulting from the different targeting modification. In vivo antitumor efficacy assay showed that the tumor inhibition effect of Au-TOS DENP-treated group (6.65 \pm 1.00 times tumor growth) was lower than that of Au-TOS-FA DENP-treated group (5.23 \pm 0.72 times tumor growth), but greater than that of free $\alpha$-TOS (7.37 \pm 0.65 times tumor growth) at the same dose of $\alpha$-TOS, suggesting the efficiency of targeting property and the advantage of dendrimer-drug nanoconjugates. In another study, D- $\alpha$-tocopherol polyethylene glycol succinate (TPGS) was conjugated with docetaxel (DTX) and paclitaxel (PTX), respectively to render the drugs with enhanced solubility and cellular toxicity. All the nanoformulations displayed enhanced water solubility of DTX 
and PTX. Cytotoxicity studies of DTX, Dendrimer-DTX (DB), DTX-loaded dendrimer-TPGS mixed micelles (DD), PTX, Dendrimer-PTX (PB) and PTX-loaded dendrimer-TPGS mixed micelles (PD) in A549, MCF-7 and $\mathrm{CHO}$ cells were conducted. In the studied concentration range, dendrimer-drug formulations showed better anticancer therapeutic efficacy than pure or free DTX and PTX for both lung and breast cancer cells. While the TPGS modified DD and PD were more cytotoxic than the corresponding plain dendrimer formulations $(\mathrm{DB}$ and $\mathrm{PB})$. What's more, the dendrimer-drug formulations showed low toxicity to the $\mathrm{CHO}$ cells, possibly resulting from the facts that the take-up way through endocytosis and the altered physiology processes of nanoformulations for cancer cells differed from those for normal cells [114].

\section{Radiotherapy}

Cytotoxic levels of radiation can be delivered to the tumor site by radionuclides labeled onto the dendrimer scaffold. A number of radionuclides such as ${ }^{131} \mathrm{I}$ [84], yittrium-90 $\left({ }^{90} \mathrm{Y}\right)$ [115], Lutetium-177 $\left({ }^{177} \mathrm{Lu}\right)$ [94], rhenium-188 $\left({ }^{188} \mathrm{Re}\right)[116]$ and strontium-89 $\left({ }^{89} \mathrm{Sr}\right)[117]$ have been used for radiotherapy in the clinic. Among these radionuclides, ${ }^{131} \mathrm{I}$ and ${ }^{177} \mathrm{Lu}$ have been labeled onto dendrimers for radiotherapy of cancer. ${ }^{131} \mathrm{I}$ has relatively long half-life $\left(t_{1 / 2}=8.01\right.$ days), appropriate radiation energy $(0.606 \mathrm{MeV}, 89.9 \%)$, and convenient labeling methods. At the same time, it has the ability for simultaneous single-photon emission computed tomography (SPECT) imaging and radiotherapy [118]. ${ }^{177} \mathrm{Lu}$ is a $\beta$ - and $\gamma$ emitting radionuclide with a physical half-life of 162 hours (6.73 days) [119,120]. Recently, we successfully labeled G5 PAMAM dendrimer with ${ }^{131} \mathrm{I}$ by the linked 3(4'-hydroxyphenyl) propionic acid-OSu (HPAO). In addition, the dendrimer periphery was modified with various targeting agents including FA [91], chlorotoxin (CTX) (Fig. 6) [91], and Buthus martensii Karsch chlorotoxin [92] for theranostics of tumors. Our studies showed that the ${ }^{131}$ I-labeled PAMAM dendrimers exhibited good targeting specificity and excellent radiotherapy efficacy to xenografted tumor models [91,92]. In another study, ${ }^{177} \mathrm{Lu}$ was labeled to the dendrimer surface by chelating with S-2-(4-Isothiocyanatobenzyl)-1,4,7,10tetraazacyclododecane tetraacetic acid [93]. Similarly, Héctor et al. [94] synthesized ${ }^{177} \mathrm{Lu}$-DOTA-dendrimer -FA-bombesin with Au NPs entrapped within the dendrimers to investigate the radiopharmaceutical potential for targeted radiotherapy and the simultaneous detection of FA receptors and gastrin-releasing peptide receptors overexpressed in T47D breast cancer cells. ${ }^{177} \mathrm{Lu}$-De-

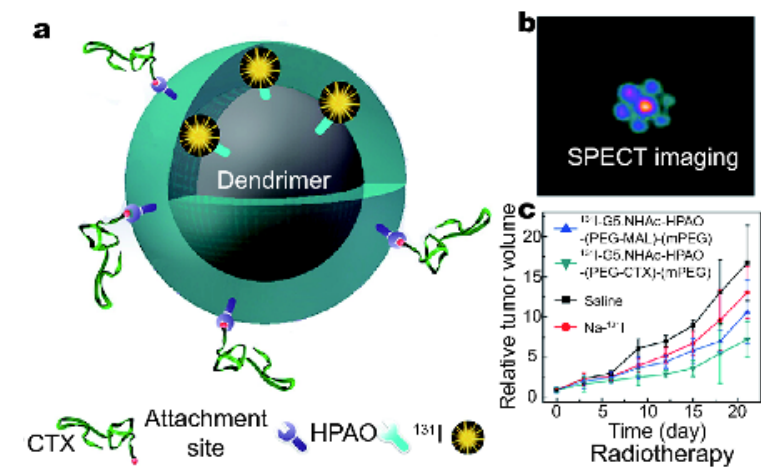

Figure 6 The structure of chlorotoxin-conjugated multifunctional dendrimers labeled with radionuclide ${ }^{131} \mathrm{I}$ (a), the SPECT images of ex vivo tumors (b) and the tumor volume (c) of C6 tumor-bearing mice after various treatments (mean $\pm \mathrm{SD}, n=5$ ). Reproduced with permission from Ref. [91]. Copyright 2015, American Chemical Society.

nAuNP-FA-bombesin was obtained with a radiochemical purity of $>95 \%$ as determined by size exclusion radio high-performance liquid chromatography. The results of the cell viability indicated that ${ }^{177} \mathrm{Lu}$-DenAuNP-FAbombesin was about 4 times more lethal than that of ${ }^{177} \mathrm{Lu}$-DenAuNP without $\mathrm{FA}$, indicating the targeted radiotherapeutic efficiency of ${ }^{177} \mathrm{Lu}-$ DenAuNP-FAbombesin.

\section{PTT}

PTT uses the heat between 41 and $45^{\circ} \mathrm{C}$ induced by PTT agents that are able to transform near-infrared (NIR) laser light to thermal energy to ablate tumor cells [121]. In order to achieve the PTT treatment of tumors, PTT agents have been modified with dendrimers to form functional nanohybrids. The PTT agents such as Au NPs with different morphologies ( $\mathrm{Au}$ nanorods [95], Au nanosheets [122] and Au nanostars [51]), copper sulfide (CuS) [98] and molybdenum sulfide $\left(\mathrm{MoS}_{2}\right)$ [97] are able to be functionalized with dendrimers as templates or stabilizers. Li et al. [95] investigated a new type of hybrid dendrimers with a core of a gold nanorod (GNR) and a shell of PEG-modified PAMAM (PEG-PAMAM) (Fig. 7). Different generations of PEG-modified cystamine-cored PAMAM (G2-G4) dendrimers were firstly synthesized and then used to stabilize the GNRs. The addition of PEG-PAMAM dendrimer did not affect the morphology of GNR. Stability test showed that PEG-PAMAM G4 dendrimer-GNR hybrids aggregated in an aqueous solution, while other generations of PEG-PAMAM enabled the formation of stable hybrids, especially the PEG-PAMAM G3 dendrimer-GNR hybrids. The following assay proved that GNR-cored PEG-PAMAM G3 dendrimers 


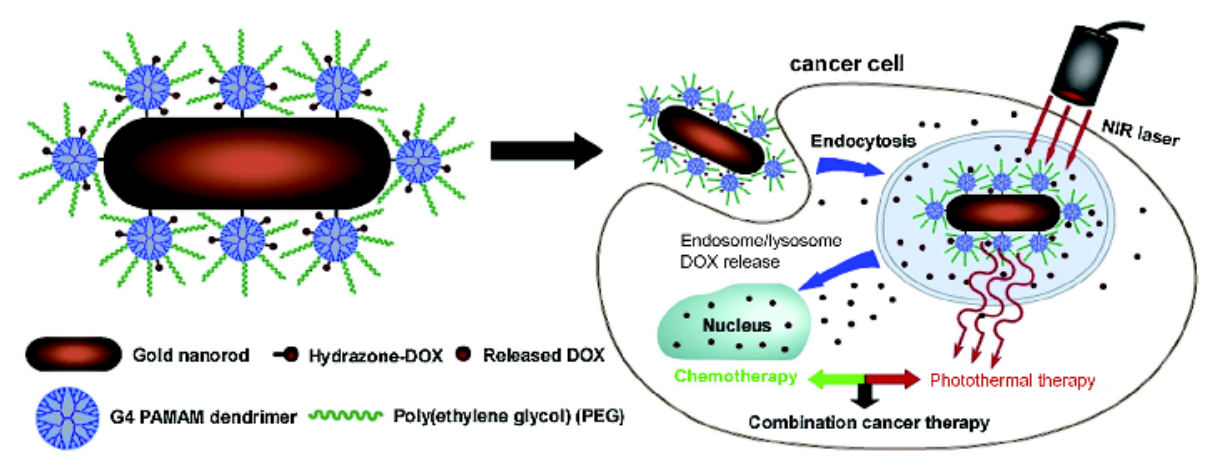

Figure 7 Schematic illustration of pH-sensitive PEGylated PAMAM dendrimer-DOX conjugate-hybridized gold nanorod (PEG-DOX-PAMAMAuNR) for combined photothermal-chemotherapy. Reproduced with permission from Ref. [95]. Copyright 2014, the Royal Society of Chemistry.

also exhibited excellent photothermal property that can be used to ablate HeLa cells and xenografted mouse tumor model under an $808 \mathrm{~nm}$ NIR laser irradiation.

In another work, Zan et al. [96] developed a kind of nanogel (NG) encapsulated with $\beta$-cyclodextrin ( $\beta$-CD)functionalized PAMAM dendrimer. Through electrostatic interaction between PAMAM and drugs, the DOX or indocyanine green (ICG) can be stably encapsulated within the NGs (DINGs). Assays of NIR light-triggered NG dissociation and drug release showed that the temperature of DINGs increased more rapidly than free ICG, presumably due to the fact that the maximum absorption peak of free ICG was at $780 \mathrm{~nm}$, while that of DINGs was at $795 \mathrm{~nm}$, quite close to the irradiation wavelength of $805 \mathrm{~nm}$. The NIR irradiation could apparently decrease the $\mathrm{IC}_{50}$ of DOX from 33 to $7 \mu \mathrm{g} \mathrm{mL} \mathrm{L}^{-1}$, showing efficient synergistic effect of combined photothermal-chemotherapy and NIR light-triggered drug release. The in vivo antitumor efficacy assay showed that the tumor growth was largely suppressed when treated with DINGs and NIR irradiation, and the tumor volume even decreased to a very small size within 16 days.

\section{PDT}

PDT is a useful method to destroy cancer cells by reactive oxygen species (ROS) and singlet oxygen that are produced by photosensitizers (PS) when exposed to visible or NIR laser light. The PS/dendrimers nanoformulations can be formed by covalent binding $[99,123,124]$, physical encapsulation $[100,125,126]$, electrostatic interaction $[101,102]$ between PS and dendrimers. Meanwhile the PS can be used as branch unit to synthesize PS-based dendrimers for photodynamic treatment of cancer [127]. Bastien et al. [99] synthesized a conjugate using the photosensitizer chlorin e6 (Ce6) and PAMAM G4.5 dendrimers (Fig. 8). Although the singlet oxygen quan- tum yield of the PAMAM G4.5-Ce6 conjugate was 2.1 times lower than that of free $\mathrm{Ce} 6$, the $\mathrm{IC}_{50}$ of G4.5-Ce6 conjugate was 7 times lower $\left(0.1 \mu \mathrm{g} \mathrm{m}^{-1}\right)$ than that of free Ce6 $\left(0.7 \mu \mathrm{g} \mathrm{mL}^{-1}\right)$ due to the higher cellular uptake of G4.5-Ce6 conjugate. Phthalocyanines (Pc) derivative with promising potential for fluorescence imaging and PDT for tumors was also encapsulated within the cavity of G4 PPI dendrimers [100]. The drug encapsulation efficiency could be up to $20 \%$ due to hydrophobic linker of Pc, and the formed nanocarrier has a particular NIR absorption at $700 \mathrm{~nm}$. Cytotoxicity assay data showed that the formulation had efficient phototoxicity $\left(\mathrm{IC}_{50}=0.9 \mu \mathrm{g} \mathrm{mL}^{-1}\right)$ after exposure to a $670 \mathrm{~nm}$ laser and low dark cytotoxicity $\left(\mathrm{IC}_{50}=28 \mu \mathrm{g} \mathrm{mL} \mathrm{m}^{-1}\right)$ to the cancer cells.

As for phosphorus dendrimers, the most used way to form PS/dendrimer formulation is electrostatic interaction. For example, the anionic phosphorus dendrimers were used to load positively charged methylene blue, and

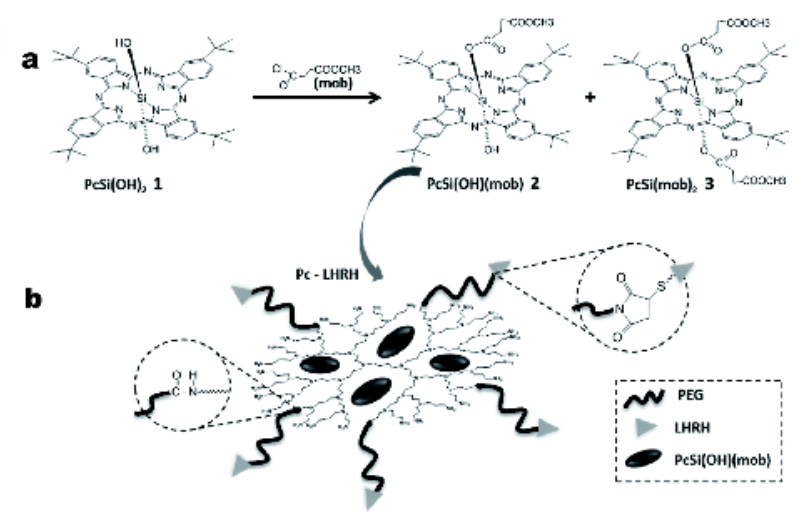

Figure 8 (a) Synthesis of mono-( $\mathrm{PcSi}(\mathrm{OH})(\mathrm{mob}), 2)$ and disubstituted $\left(\mathrm{PcSi}(\mathrm{mob})_{2}, 3\right)$ derivatives of the silicon phthalocyanine $\left(\mathrm{PcSi}(\mathrm{OH})_{2}, \mathbf{1}\right)$. (b) Schematic representation of tumor targeted theranostic platform based on phthalocyanine-loaded dendrimer ( $\mathrm{Pc}$-Luteinizing Hormone Releasing Hormone). Reproduced with permission from Ref. [100]. Copyright 2013, American Chemical Society. 
the cationic phosphorus dendrimers were used to encapsulate negatively charged rose bengal (RB) both through electrostatic interaction [101]. The RB-phosphorus dendrimer complex processed cationic charges. RB and dendrimer showed no "dark" toxicity in three cancer cell lines (ASZ, BSZ, and CSZ, respectively). When being irradiated, $R B$ decreased the cell viability only to $53 \%$ in CSZ cells at the concentration of $0.75 \mu \mathrm{mol} \mathrm{L}^{-1}$, while the complex exhibited almost $85 \%-95 \%$ phototoxicity against all three cell lines at the concentration of $0.5 \mu \mathrm{mol} \mathrm{L}{ }^{-1}$, indicating the efficient PDT property of rose bengal-phosphorus dendrimer complex [102].

\section{Gene therapy}

Anionic nucleic acid can be easily condensed by cationic dendrimers with plenty of amine groups by electrostatic compression. The formed nucleic acid/dendrimer polyplexes can be surface modified to have different functionalities and the compressed nucleic acid can be protected from enzymatic degradation. What's more, some dendrimers including PAMAM, PPI and poly(ether imine) with a plenty of tertiary amine groups can exert a "proton sponge" effect to help polyplexes escape from lysosomes. Therefore, the nucleic acid can be well protected and efficiently released to the cytoplasm and expressed [128]. Among these dendrimers, PAMAM dendrimer [88,129,130], phosphorus dendrimer [108] and PPI dendrimer [109,57] have been mostly used. A range of modification strategies have been adopted to reduce the cytotoxicity of dendrimers such as dodecylation [103,131], arginine-modification [132], or PEGylation. Chang et al. [103] used dodecylated G2, G3 and G4 PAMAM dendrimers to deliver luciferase (Luc)-targeted siRNA or Bcl-2 siRNA to HeLa cells and MDA-MB231 cells for gene silencing. Compared with unmodified G2, G3 and G4 PAMAM dendrimers, dodecylated G2, G3 and G4 showed significantly higher gene silencing efficacy. Especially, $84.6 \%$ of Luc gene was knocked down by dodecylated G4 dendrimers, meanwhile more than $90 \%$ of cells survived, showing the best delivery efficiency.

Interestingly, some studies have shown that after entrapment of Au NPs within the interiors of dendrimers, the 3D spherical shape of dendrimers are well reserved, consequently featuring much more binding sites with DNA than dendrimers without $\mathrm{Au}$ cores [104]. So the capability of dendrimers to compact pDNA was significantly improved, which is essential for improved gene delivery [105,106]. Hou et al. [107] designed a vector of Au DENPs partially modified with $m$ PEG for non-viral pDNA/siRNA delivery. The pDNA encoding Luc or en- hanced green fluorescent protein and the Bcl-2 siRNA were successfully packaged, respectively, by the partially PEGylated Au DENPs for effective delivery to HeLa cells to express the related proteins or to silence the expression of Bcl-2 protein. Three different cationic dendrimers (PAMAM, phosphorus and carbosilane) with anticancer siBcl-xl, siBcl-2, siMcl-1 siRNAs and a siScrambled sequence were investigated by Ionov et al. [108] to study the mechanisms of interaction. Circular dichroism spectroscopy showed that the general shape of the siRNA spectra was unaltered by dendrimers after their interaction. Through gel electrophoresis, it was proven that the dendrimer/siRNA polyplexes well protected the siRNA from RNase degradation and only the addition of heparin led to its release from the polyplexes.

Studies have shown that fluorinated dendrimers can improve the transfection efficacy and decrease the cytotoxicity for gene delivery applications $[109,133]$. Wang et al. [133] synthesized the perfluoro acid-modified G5 PAMAM dendrimers, which are able to achieve excellent gene transfection efficacy in several cell lines (higher than 90\% in HEK293 and HeLa cells) at extremely low N/P ratios. In addition, the fluorinated dendrimer shows excellent serum resistance and exhibits high gene transfection efficacy even in medium containing $50 \%$ fetal bovine serum. Apart from PAMAM dendrimers, different generations of PPI dendrimers were also studied as gene vectors. In order to improve the transfection efficacy and decrease the cytotoxicity of PPI dendrimers, Liu et al. [109] prepared a series of fluorinated PPI dendrimers including G3, G4, and G5 PPI dendrimers. The studied fluorinated PPI dendrimers showed comparable or superior transfection efficiency to that of Lipofectamine 2000, jetPEI, branched poly(ethyleneimine), SuperFect, PolyFect, as well as arginine-modified dendrimers in HEK293, HeLa cells and 3D multicellular spheroids.

\section{Combination therapy}

The commonly used chemotherapeutic agents often have limited therapeutic effectiveness because of undesirable side effects, multidrug resistance and poor drug delivery efficiency to the interior of the solid tumor due to the abnormal vessel and anoxic microenvironment of tumors [134]. Each mode of radiotherapy, PTT, PDT and gene therapy has its own disadvantages and limitations. Therefore, combination therapy seems to be necessary to improve the therapeutic effect $[51,97,135]$. For instance, the combination of PTT and chemotherapy (photothermal-chemotherapy) has been proven to be more effective than the respective monotherapy because additive 
or synergistic effects can be realized [136-138]. Dendrimers can also act as a valuable platform for combination cancer therapy. Li et al. [86] prepared G4 PAMAM dendrimer-stabilized GNRs to conjugate DOX with a $\mathrm{pH}$ sensitive linker for combined cancer photothermal-chemotherapy under in vitro and in vivo conditions. Both in vitro cytotoxicity and live cell staining assays validated the synergistic photothermal-chemotherapy effect of PEGDOX-PAMAM-AuNR on HeLa cells. The in vivo studies of the PEG-DOX-PAMAM-AuNR (irradiation + ) group exhibited remarkable tumor growth delay on day 16, underscoring the great potential of PEG-DOX-PAMAMAuNR for combination cancer therapy. For combination radiotherapeutic-photothermal therapy, the dendrimer nanoplatfrom has been designed to label with radioisotopes and entrap or stabilize some nanoparticulate PTT agents, such as Au NPs [126]. Besides these two types of combination described above, there are other combination therapy strategies including PTT-PDT $[123,139,140]$, genetic-chemotherapy $[134,135]$, geneticPDT [141] and genetic-PTT [51,97].

Gene therapy are often used as a complementary therapy to combine with other approaches. For instance, Shi's group developed two different nanoplatforms for combination gene and PTT of tumors based on PAMAM dendrimer-stabilized $\mathrm{Au}$ nanostars (NSs) [51] or $\mathrm{MoS}_{2}$ nanoflakes [97]. In their study, RGD-modified dendrimer-stabilized Au NSs (RGD-Au DSNSs) with a mean diameter of $52.2 \pm 14.2 \mathrm{~nm}$ for the Au NSs exhibited an apparent surface plasmon resonance (SPR) peak at around $800 \mathrm{~nm}$. The RGD-Au DSNSs were used to compact Bcl-2 siRNA for targeted PTT and gene therapy of cancer cells in vitro and the xenografted tumor model in vivo under the irradiation of an $808 \mathrm{~nm}$ laser (Fig. 9) [51]. Different from the $\mathrm{Au} \mathrm{NSs}, \mathrm{MoS}_{2}$ nanoflakes displayed strong NIR absorption in a wide spectral range. Combinational PTT and gene silencing of cancer cells in vitro showed that the cell inhibition efficacy followed the order of G5- $\mathrm{MoS}_{2} /$ siRNA polyplexes+laser (21.0\%) > G5$\mathrm{MoS}_{2}+$ laser (45.8\%) > G5- $\mathrm{MoS}_{2} /$ siRNA polyplexes $(68.7 \%)$, demonstrating significant enhanced cancer cell inhibition efficacy [97].

\section{CONCLUSIONS AND FUTURE PERSPECTIVES}

In summary, this review has described the recent advances of different dendrimer-based platforms for various strategies developed for cancer therapy. The periphery of dendrimers can be diversely functionalized with PEG, zwitterions, glycosyl, and targeting agents to improve the

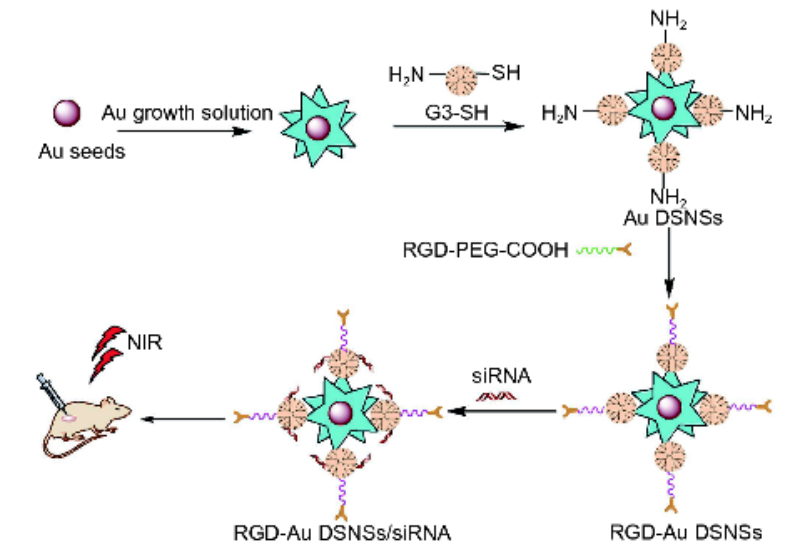

Figure 9 Schematic illustration of the formation of the RGD-Au DSNSs for $\mathrm{CT} /$ thermal imaging and combinational therapy of tumors. Reproduced with permission from Ref. [51]. Copyright 2016, WILEY$\mathrm{VCH}$.

therapeutic efficacy. The unique structural properties of dendrimer platform enable the drug to be physically loaded within the dendrimer interior via hydrophobic interactions or covalently conjugated onto the dendrimer surface via covalent reaction. Meanwhile radioisotopes and other chemical agents can be introduced to the dendrimer surface for radiotherapy, photothermal and photodynamic therapy. Apart from the photosensitive materials like ICG and IR-780, a range of inorganic NPs such as CuS NPs, Au NSs and $\mathrm{MoS}_{2}$ nanoflakes have been integrated with dendrimers via entrapment or stabilization strategy for PTT of tumors. The inherent surface cationic amines of dendrimers not only enable the diverse modification but also make it possible to condense nucleic acid materials for gene delivery. More importantly, the dendrimers can also serve as a platform for combination cancer therapy to induce combined or synergistic therapeutic efficacy. Therefore, dendrimers have been truly demonstrated as a unique platform for construction of different multifunctional nanoplatforms for cancer therapy applications.

Although many studies have been focused on the improvement and optimization of dendrimer-based platform for cancer therapy, dendrimer-based systems with higher biocompatibility, enhanced efficacy of treatment and metabolism mechanism still remain to be explored. For example, zwitterion-modified dendrimers with antifouling properties have shown to be protein-resistant [45] and antifouling dendrimer-entrapped gold nanoparticles can be used for enhanced CT imaging of blood pool and tumors [46]; however the antifouling dendrimer-based drug delivery or theranostic platforms have not been re- 
ported in the literature. Furthermore, apart from ${ }^{131} \mathrm{I}$ and ${ }^{77} \mathrm{Lu}$, there are few other radionuclides have been introduced to dendrimers for radiotherapy. X-ray and gamma-ray radiation by irradiator have been reported to be effective for radiotherapy with radiosensitizer for radiation enhancement effect [142,143]; however this radiotherapy mode has not been combined with dendrimer-based nanodevices. In addition, by combination of dendrimers with other vectors such as carbon nanotubes [144] and laponite [145], more advantages for cancer therapy can be endowed. For instance, dendrimermodified carbon nanotubes enabled high drug payload and encapsulation efficiency both up to $97.8 \%$ and can be used for targeted and $\mathrm{pH}$-responsive delivery of DOX into cancer cells [144]. However, these studies need to be further explored for in vivo tumor model investigations.

Although the dendrimer-based strategies for antitumor therapy have been well studied, much room remains to be explored and addressed to improve their efficacy of treatment and find out their metabolic mechanism of safety concerns. The clinical translation of dendrimers has not yet been achieved. Currently, DEP ${ }^{\circledR}$ cabazitaxel has received regulatory and ethics approval to commence its phase I/II clinical trial. It is the second product from Starpharma's $\mathrm{DEP}^{\circledR}$ platform to enter the clinic following the $\mathrm{DEP}^{\circ}$ docetaxel, which delivered positive phase I clinical results in 2017 and recently progressed to phase II. The reproducible benefits observed for DEP ${ }^{\circledR}$ docetaxel and $\mathrm{DEP}^{\circledast}$ cabazitaxel in preclinical models include decreased bone marrow toxicity and enhanced efficacy, and in both cases $\mathrm{DEP}^{\star}$ has also allowed for a detergent-free formulation resulting in significant additional benefits for patients (http://www.starpharma.com). Hence, there is still long way to go for the effective development of dendrimer-based nanomedicine. Improvements can be made through deep understanding the tumor microenvironment, tumor metabolism, and tumor metastasis to further design suitable multifunctional dendrimer-based platforms for enhanced therapy.

\section{Received 10 February 2018; accepted 2 April 2018; published online 28 April 2018}

1 Tomalia DA, Naylor AM, Goddard WA. Starburst dendrimers: molecular-level control of size, shape, surface chemistry, topology, and flexibility from atoms to macroscopic matter. Angew Chem Int Ed, 1990, 29: 138-175

2 Tomalia DA, Baker H, Dewald J, et al. A new class of polymers: starburst-dendritic macromolecules. Polym J, 1985, 17: 117-132

3 Hawker CJ, Frechet JMJ. Preparation of polymers with controlled molecular architecture. A new convergent approach to dendritic macromolecules. J Am Chem Soc, 1990, 112: 7638-7647
4 Kawaguchi T, Walker KL, Wilkins CL, et al. Double exponential dendrimer growth. J Am Chem Soc, 1995, 117: 2159-2165

5 Wooley KL, Hawker CJ, Frechet JMJ. Hyperbranched macromolecules via a novel double-stage convergent growth approach. J Am Chem Soc, 1991, 113: 4252-4261

6 Wu P, Feldman AK, Nugent AK, et al. Efficiency and fidelity in a click-chemistry route to triazole dendrimers by the copper(I)catalyzed ligation of azides and alkynes. Angew Chem Int Ed, 2004, 43: 3928-3932

7 Maraval V, Pyzowski J, Caminade AM, et al. "Lego" chemistry for the straightforward synthesis of dendrimers. J Org Chem, 2003, 68: 6043-6046

8 Esfand R, Tomalia DA. Poly(amidoamine) (PAMAM) dendrimers: from biomimicry to drug delivery and biomedical applications. Drug Discovery Today, 2001, 6: 427-436

9 Brothers II HM, Piehler LT, Tomalia DA. Slab-gel and capillary electrophoretic characterization of polyamidoamine dendrimers. J Chromatography A, 1998, 814: 233-246

10 Hecht S, Fréchet JMJ. Dendritic encapsulation of function: applying nature's site isolation principle from biomimetics to materials science. Angew Chem Int Ed, 2001, 40: 74-91

11 Dandliker PJ, Diederich F, Zingg A, et al. Dendrimers with porphyrin cores: Synthetic models for globular heme proteins. Helv Chim Acta, 1997, 80: 1773-1801

12 Jiang DL, Aida T. A dendritic iron porphyrin as a novel haemoprotein mimic: effects of the dendrimer cage on dioxygenbinding activity. Chem Commun, 1996, 1523

13 Weyermann P, Gisselbrecht JP, Boudon C, et al. Dendritic iron porphyrins with tethered axial ligands: new model compounds for cytochromes. Angew Chem Int Ed, 1999, 38: 3215-3219

14 Richter-Egger DL, Tesfai A, Tucker SA. Spectroscopic investigations of poly(propyleneimine)dendrimers using the solvatochromic probe phenol blue and comparisons to poly (amidoamine) dendrimers. Anal Chem, 2001, 73: 5743-5751

15 Shao N, Su Y, Hu J, et al. Comparison of generation 3 polyamidoamine dendrimer and generation 4 polypropylenimine dendrimer on drug loading, complex structure, release behavior, and cytotoxicity. Int J Nanomed, 2011, 6: 3361-3372

16 Sadler K, Tam JP. Peptide dendrimers: applications and synthesis. Rev Mol Biotechnol, 2002, 90: 195-229

17 Ionov M, Wróbel D, Gardikis K, et al. Effect of phosphorus dendrimers on DMPC lipid membranes. Chem Phys Lipids, 2012, 165: 408-413

18 Tomalia DA, Esfand R. Dendrons, dendrimers and dendrigrafts. Chem Ind, 1997, 416-420

19 Buhleier E, Wehner W, Vögtle F. "Cascade"- and "nonskid-chainlike" syntheses of molecular cavity topologies. Synthesis, 1978, 1978: $155-158$

20 Ly TU, Tran NQ, Hoang TKD, et al. Pegylated dendrimer and its effect in fluorouracil loading and release for enhancing antitumor activity. J Biomed Nanotechnol, 2013, 9: 213-220

21 Kesharwani P, Tekade RK, Jain NK. Generation dependent cancer targeting potential of poly(propyleneimine) dendrimer. Biomaterials, 2014, 35: 5539-5548

22 Roberts BP, Scanlon MJ, Krippner GY, et al. Molecular dynamics of poly(L-lysine) dendrimers with naphthalene disulfonate caps. Macromolecules, 2009, 42: 2775-2783

23 Ohsaki $\mathrm{M}$, Okuda $\mathrm{T}$, Wada $\mathrm{A}$, et al. In vitro gene transfection using dendritic poly(L-lysine). Bioconjugate Chem, 2002, 13: 510-517 
24 Kratz F. Albumin as a drug carrier: Design of prodrugs, drug conjugates and nanoparticles. J Control Release, 2008, 132: 171183

25 Fanali G, di Masi A, Trezza V, et al. Human serum albumin: From bench to bedside. Mol Aspects Med, 2012, 33: 209-290

26 Maraval V, Caminade AM, Majoral JP, et al. Dendrimer design: how to circumvent the dilemma of a reduction of steps or an increase of function multiplicity? Angew Chem Int Ed, 2003, 42: 1822-1826

27 Gurdag S, Khandare J, Stapels S, et al. Activity of dendrimer -methotrexate conjugates on methotrexate-sensitive and -resistant cell lines. Bioconjugate Chem, 2006, 17: 275-283

28 Patri AK, Myc A, Beals J, et al. Synthesis and in vitro testing of J591 antibody-dendrimer conjugates for targeted prostate cancer therapy. Bioconjugate Chem, 2004, 15: 1174-1181

29 Svenson S, Tomalia DA. Dendrimers in biomedical applications -reflections on the field. Adv Drug Deliver Rev, 2012, 64: 102115

30 Tajarobi F, El-Sayed M, Rege BD, et al. Transport of poly amidoamine dendrimers across Madin-Darby canine kidney cells. Int J Pharm, 2001, 215: 263-267

31 Toscano MD, Müller MM, Hilvert D. Enhancing activity and controlling stereoselectivity in a designed PLP-dependent aldolase. Angew Chem Int Ed, 2007, 46: 4468-4470

32 Khandare JJ, Jayant S, Singh A, et al. Dendrimer versus linear conjugate: influence of polymeric architecture on the delivery and anticancer effect of paclitaxel. Bioconjugate Chem, 2006, 17: 1464-1472

33 Kono K, Liu M, Fréchet JMJ. Design of dendritic macromolecules containing folate or methotrexate residues. Bioconjugate Chem, 1999, 10: 1115-1121

34 Morgan MT, Carnahan MA, Immoos CE, et al. Dendritic molecular capsules for hydrophobic compounds. J Am Chem Soc, 2003, 125: 15485-15489

35 Ziemba B, Janaszewska $\mathrm{A}$, Ciepluch $\mathrm{K}$, et al. In vivo toxicity of poly(propyleneimine) dendrimers. J Biomed Mater Res, 2011, 99A: 261-268

36 Cheng Y, Zhao L, Li Y, et al. Design of biocompatible dendrimers for cancer diagnosis and therapy: current status and future perspectives. Chem Soc Rev, 2011, 40: 2673-2703

37 Zhu J, Shi X. Dendrimer-based nanodevices for targeted drug delivery applications. J Mater Chem B, 2013, 1: 4199-4211

38 Shen M, Shi X. Dendrimer-based organic/inorganic hybrid nanoparticles in biomedical applications. Nanoscale, 2010, 2: 15961610

39 Choi JS, Nam K, Park JY, et al. Enhanced transfection efficiency of PAMAM dendrimer by surface modification with L-arginine. J Control Release, 2004, 99: 445-456

40 Madaan K, Kumar S, Poonia N, et al. Dendrimers in drug delivery and targeting: Drug-dendrimer interactions and toxicity issues. J Pharm Bioall Sci, 2014, 6: 139-150

41 Kesharwani P, Iyer AK. Recent advances in dendrimer-based nanovectors for tumor-targeted drug and gene delivery. Drug Discovery Today, 2015, 20: 536-547

42 Peng C, Zheng L, Chen Q, et al. PEGylated dendrimer-entrapped gold nanoparticles for in vivo blood pool and tumor imaging by computed tomography. Biomaterials, 2012, 33: 1107-1119

43 Thakur S, Tekade RK, Kesharwani P, et al. The effect of polyethylene glycol spacer chain length on the tumor-targeting potential of folate-modified PPI dendrimers. J Nanopart Res, 2013,
15: 1625

44 Jia L, Xu JP, Wang H, et al. Polyamidoamine dendrimers surfaceengineered with biomimetic phosphorylcholine as potential drug delivery carriers. Colloids Surfs B-Biointerfaces, 2011, 84: 49-54

45 Wang L, Wang Z, Ma G, et al. Reducing the cytotoxity of poly (amidoamine) dendrimers by modification of a single layer of carboxybetaine. Langmuir, 2013, 29: 8914-8921

46 Xiong Z, Wang Y, Zhu J, et al. Dendrimers meet zwitterions: development of a unique antifouling nanoplatform for enhanced blood pool, lymph node and tumor CT imaging. Nanoscale, 2017, 9: $12295-12301$

47 Kolhatkar RB, Kitchens KM, Swaan PW, et al. Surface acetylation of polyamidoamine (PAMAM) dendrimers decreases cytotoxicity while maintaining membrane permeability. Bioconjugate Chem, 2007, 18: 2054-2060

48 Zhang M, Guo R, Kéri M, et al. Impact of dendrimer surface functional groups on the release of doxorubicin from dendrimer carriers. J Phys Chem B, 2014, 118: 1696-1706

49 Chen $\mathrm{Q}$, Wang $\mathrm{H}$, Liu $\mathrm{H}$, et al. Multifunctional dendrimer-entrapped gold nanoparticles modified with RGD peptide for targeted computed tomography/magnetic resonance dual-modal imaging of tumors. Anal Chem, 2015, 87: 3949-3956

$50 \mathrm{Li} \mathrm{Q}, \mathrm{Gu} \mathrm{W}$, Liu K, et al. RGD conjugated, Cy5.5 labeled polyamidoamine dendrimers for targeted near-infrared fluorescence imaging of esophageal squamous cell carcinoma. RSC Adv, 2016, 6: 74560-74566

51 Wei P, Chen J, Hu Y, et al. Dendrimer-stabilized gold nanostars as a multifunctional theranostic nanoplatform for CT imaging, photothermal therapy, and gene silencing of tumors. Adv Healthcare Mater, 2016, 5: 3203-3213

52 Kong L, Alves CS, Hou W, et al. RGD peptide-modified dendrimer-entrapped gold nanoparticles enable highly efficient and specific gene delivery to stem cells. ACS Appl Mater Interfaces, 2015, 7: 4833-4843

53 Zhu J, Fu F, Xiong Z, et al. Dendrimer-entrapped gold nanoparticles modified with RGD peptide and alpha-tocopheryl succinate enable targeted theranostics of cancer cells. Colloids Surfs B-Biointerfaces, 2015, 133: 36-42

54 Lee S, Jung S, Koo H, et al. Nano-sized metabolic precursors for heterogeneous tumor-targeting strategy using bioorthogonal click chemistry in vivo. Biomaterials, 2017, 148: 1-15

55 Fu F, Wu Y, Zhu J, et al. Multifunctional lactobionic acid-modified dendrimers for targeted drug delivery to liver cancer cells: investigating the role played by PEG spacer. ACS Appl Mater Interfaces, 2014, 6: 16416-16425

56 Hashemi M, Ayatollahi S, Parhiz H, et al. PEGylation of polypropylenimine dendrimer with alkylcarboxylate chain linkage to improve DNA delivery and cytotoxicity. Appl Biochem Biotechnol, 2015, 177: 1-17

57 Franiak-Pietryga I, Ostrowska K, Maciejewski H, et al. PPI-G4 glycodendrimers upregulate TRAIL-induced apoptosis in chronic lymphocytic leukemia cells. Macromol Biosci, 2017, 17: 1600169

58 Klementieva O, Aso E, Filippini D, et al. Effect of poly(propylene imine) glycodendrimers on $\beta$-amyloid aggregation in vitro and in APP/PS1 transgenic mice, as a model of brain amyloid deposition and Alzheimer's disease. Biomacromolecules, 2013, 14: 35703580

59 Xiong Z, Wang Y, Zhu J, et al. Gd-chelated poly(propylene imine) dendrimers with densely organized maltose shells for enhanced MR imaging applications. Biomater Sci, 2016, 4: 1622-1629 
60 Tietze S, Schau I, Michen S, et al. A poly(propyleneimine) dendrimer-based polyplex-system for single-chain antibody-mediated targeted delivery and cellular uptake of siRNA. Small, 2017, 13: 1700072

61 Kesharwani P, Tekade RK, Jain NK. Generation dependent safety and efficacy of folic acid conjugated dendrimer based anticancer drug formulations. Pharm Res, 2015, 32: 1438-1450

62 Hashemi M, Tabatabai SM, Parhiz H, et al. Gene delivery efficiency and cytotoxicity of heterocyclic amine-modified PAMAM and PPI dendrimers. Mater Sci Eng-C, 2016, 61: 791-800

63 Park JW, Mok H, Park TG. Physical adsorption of PEG grafted and blocked poly-L-lysine copolymers on adenovirus surface for enhanced gene transduction. J Control Release, 2010, 142: 238244

64 Jain K, Gupta U, Jain NK. Dendronized nanoconjugates of lysine and folate for treatment of cancer. Eur J Pharm BioPharm, 2014, 87: 500-509

65 Hayder M, Poupot M, Baron M, et al. A phosphorus-based dendrimer targets inflammation and osteoclastogenesis in experimental arthritis. Sci Translational Med, 2011, 3: 81ra35

66 Shcharbin D, Dzmitruk V, Shakhbazau A, et al. Fourth generation phosphorus-containing dendrimers: prospective drug and gene delivery carrier. Pharmaceutics, 2011, 3: 458-473

67 Dobrovolskaia MA, Aggarwal P, Hall JB, et al. Preclinical studies to understand nanoparticle interaction with the immune system and its potential effects on nanoparticle biodistribution. Mol Pharmaceutics, 2008, 5: 487-495

68 Peer D, Karp JM, Hong S, et al. Nanocarriers as an emerging platform for cancer therapy. Nat Nanotechnol, 2007, 2: 751-760

69 Dobrovolskaia MA, McNeil SE. Immunological properties of engineered nanomaterials. Nat Nanotechnol, 2007, 2: 469-478

70 Wang P, Yang J, Zhou B, et al. Antifouling manganese oxide nanoparticles: synthesis, characterization, and applications for enhanced MR imaging of tumors. ACS Appl Mater Interfaces, 2017, 9: 47-53

71 Ma D, Chen J, Luo Y, et al. Zwitterion-coated ultrasmall iron oxide nanoparticles for enhanced $\mathrm{T}_{1}$-weighted magnetic resonance imaging applications. J Mater Chem B, 2017, 5: 72677273

72 Cao Y, He Y, Liu H, et al. Targeted CT imaging of human hepatocellular carcinoma using low-generation dendrimer-entrapped gold nanoparticles modified with lactobionic acid. J Mater Chem B, 2015, 3: 286-295

$73 \mathrm{Oh} \mathrm{MH}$, Lee $\mathrm{N}$, Kim H, et al. Large-scale synthesis of bioinert tantalum oxide nanoparticles for X-ray computed tomography imaging and bimodal image-guided sentinel lymph node mapping. J Am Chem Soc, 2011, 133: 5508-5515

74 Appelhans D, Klajnert-Maculewicz B, Janaszewska A, et al. Dendritic glycopolymers based on dendritic polyamine scaffolds: view on their synthetic approaches, characteristics and potential for biomedical applications. Chem Soc Rev, 2015, 44: 3968-3996

75 Torchilin V. Tumor delivery of macromolecular drugs based on the EPR effect. Adv Drug Deliver Rev, 2011, 63: 131-135

76 Maruyama K. Intracellular targeting delivery of liposomal drugs to solid tumors based on EPR effects. Adv Drug Deliver Rev, 2011, 63: 161-169

77 Sisson AL, Steinhilber D, Rossow T, et al. Biocompatible functionalized polyglycerol microgels with cell penetrating properties. Angew Chem Int Ed, 2009, 48: 7540-7545

78 Sharma AK, Gothwal A, Kesharwani P, et al. Dendrimer na- noarchitectures for cancer diagnosis and anticancer drug delivery. Drug Discovery Today, 2017, 22: 314-326

79 Kesharwani P, Tekade RK, Jain NK. Formulation development and in vitro-in vivo assessment of the fourth-generation PPI dendrimer as a cancer-targeting vector. Nanomedicine, 2014, 9: 2291-2308

80 Campbell IG, Jones TA, Foulkes WD, et al. Polate-binding protein is a marker for ovarian-cancer. Cancer Res, 1991, 51: 53295338

81 Weitman SD, Lark RH, Coney LR, et al. Distribution of the folate receptor GP38 in normal and malignant-cell lines and tissues. Cancer Res, 1992, 52: 3396-3401

82 Qiao Z, Shi X. Dendrimer-based molecular imaging contrast agents. Prog Polymer Sci, 2015, 44: 1-27

83 Fan Y, Sun W, Shi X. Design and biomedical applications of poly (amidoamine)-dendrimer-based hybrid nanoarchitectures. Small Methods, 2017, 1: 1700224

84 Tomalia DA, Hall M, Hedstrand DM. Starburst dendrimers. III. The importance of branch junction symmetry in the development of topological shell molecules. J Am Chem Soc, 1987, 109: 16011603

85 Tomalia DA, Fréchet JMJ. Discovery of dendrimers and dendritic polymers: A brief historical perspective. J Polym Sci A Polym Chem, 2002, 40: 2719-2728

86 Li X, Takashima M, Yuba E, et al. PEGylated PAMAM dendrimer-doxorubicin conjugate-hybridized gold nanorod for combined photothermal-chemotherapy. Biomaterials, 2014, 35: 6576-6584

87 Shi X, Lee I, Chen X, et al. Influence of dendrimer surface charge on the bioactivity of 2-methoxyestradiol complexed with dendrimers. Soft Matter, 2010, 6: 2539-2545

88 Zhang $\mathrm{C}$, Pan D, Li J, et al. Enzyme-responsive peptide dendrimer-gemcitabine conjugate as a controlled-release drug delivery vehicle with enhanced antitumor efficacy. Acta Biomater, 2017, 55: 153-162

89 Zhu J, Zheng L, Wen S, et al. Targeted cancer theranostics using alpha-tocopheryl succinate-conjugated multifunctional dendrimer-entrapped gold nanoparticles. Biomaterials, 2014, 35: 7635-7646

90 Golshan M, Salami-Kalajahi M, Roghani-Mamaqani H, et al. Poly (propylene imine) dendrimer-grafted nanocrystalline cellulose: Doxorubicin loading and release behavior. Polymer, 2017, 117: 287-294

91 Zhu J, Zhao L, Cheng Y, et al. Radionuclide ${ }^{131}$ I-labeled multifunctional dendrimers for targeted SPECT imaging and radiotherapy of tumors. Nanoscale, 2015, 7: 18169-18178

92 Cheng Y, Zhu J, Zhao L, et al. ${ }^{131}$ I-labeled multifunctional dendrimers modified with BmK CT for targeted SPECT imaging and radiotherapy of gliomas. Nanomedicine, 2016, 11: 1253-1266

93 Hector M, Guillermina F, Flor de MR, et al. Lu-177-dendrimer conjugated to folate and bombesin with gold nanoparticles in the dendritic cavity: A potential theranostic radiopharmaceutical. J Nanomater, 2016, 1039258

94 Mendoza-Nava H, Ferro-Flores G, Ramírez FM, et al. Fluorescent, plasmonic, and radiotherapeutic properties of the ${ }^{177} \mathrm{Lu}-$ dendrimer-AuNP-folate-bombesin nanoprobe located inside cancer cells. Mol Imag, 2017, 16: 153601211770476

95 Li X, Takeda K, Yuba E, et al. Preparation of PEG-modified PAMAM dendrimers having a gold nanorod core and their application to photothermal therapy. J Mater Chem B, 2014, 2: 
4167-4176

96 Zan M, Li J, Huang M, et al. Near-infrared light-triggered drug release nanogels for combined photothermal-chemotherapy of cancer. Biomater Sci, 2015, 3: 1147-1156

97 Kong L, Xing L, Zhou B, et al. Dendrimer-modified $\mathrm{MoS}_{2}$ nanoflakes as a platform for combinational gene silencing and photothermal therapy of tumors. ACS Appl Mater Interfaces, 2017, 9: 15995-16005

98 Zhou Z, Wang Y, Yan Y, et al. Dendrimer-templated ultrasmall and multifunctional photothermal agents for efficient tumor ablation. ACS Nano, 2016, 10: 4863-4872

99 Bastien E, Schneider R, Hackbarth S, et al. PAMAM G4.5chlorin-e6 dendrimeric nanoparticles for enhanced photodynamic effects. Photochem Photobiol Sci, 2015, 14: 2203-2212

100 Taratula O, Schumann C, Naleway MA, et al. A multifunctional theranostic platform based on phthalocyanine-loaded dendrimer for image-guided drug delivery and photodynamic therapy. Mol Pharmaceutics, 2013, 10: 3946-3958

101 Dabrzalska M, Zablocka M, Mignani S, et al. Phosphorus dendrimers and photodynamic therapy. Spectroscopic studies on two dendrimer-photosensitizer complexes: Cationic phosphorus dendrimer with rose bengal and anionic phosphorus dendrimer with methylene blue. Int J Pharm, 2015, 492: 266-274

102 Dabrzalska M, Janaszewska A, Zablocka M, et al. Cationic phosphorus dendrimer enhances photodynamic activity of rose bengal against basal cell carcinoma cell lines. Mol Pharmaceutics, 2017, 14: 1821-1830

103 Chang H, Zhang Y, Li L, et al. Efficient delivery of small interfering RNA into cancer cells using dodecylated dendrimers. J Mater Chem B, 2015, 3: 8197-8202

104 Shan Y, Luo T, Peng C, et al. Gene delivery using dendrimerentrapped gold nanoparticles as nonviral vectors. Biomaterials, 2012, 33: 3025-3035

105 Qiu J, Kong L, Cao X, et al. Dendrimer-entrapped gold nanoparticles modified with $\beta$-cyclodextrin for enhanced gene delivery applications. RSC Adv, 2016, 6: 25633-25640

106 Hou W, Wen S, Guo R, et al. Partially acetylated dendrimerentrapped gold nanoparticles with reduced cytotoxicity for gene delivery applications. J Nanosci Nanotechnol, 2015, 15: 40944105

107 Hou W, Wei P, Kong L, et al. Partially PEGylated dendrimerentrapped gold nanoparticles: a promising nanoplatform for highly efficient DNA and siRNA delivery. J Mater Chem B, 2016, 4: 2933-2943

108 Ionov M, Lazniewska J, Dzmitruk V, et al. Anticancer siRNA cocktails as a novel tool to treat cancer cells. Part (A). Mechanisms of interaction. Int J Pharm, 2015, 485: 261-269

109 Liu H, Wang Y, Wang M, et al. Fluorinated poly(propylenimine) dendrimers as gene vectors. Biomaterials, 2014, 35: 5407-5413

110 Guo R, Shi X. Dendrimers in cancer therapeutics and diagnosis. Curr Drug Metab, 2012, 13: 1097-1109

111 Fleige E, Quadir MA, Haag R. Stimuli-responsive polymeric nanocarriers for the controlled transport of active compounds: Concepts and applications. Adv Drug Deliver Rev, 2012, 64: 866884

112 D'Emanuele A, Attwood D. Dendrimer-drug interactions. Adv Drug Deliver Rev, 2005, 57: 2147-2162

113 Liu X, Liu C, Chen C, et al. Targeted delivery of dicer-substrate siRNAs using a dual targeting peptide decorated dendrimer delivery system. NanoMed-Nanotechnol Biol Med, 2014, 10: 1627-
1636

114 Pooja D, Kulhari H, Singh MK, et al. Dendrimer-TPGS mixed micelles for enhanced solubility and cellular toxicity of taxanes. Colloids Surfs B-Biointerfaces, 2014, 121: 461-468

115 D'Huyvetter M, Xavier C, Caveliers V, et al. Radiolabeled nanobodies as theranostic tools in targeted radionuclide therapy of cancer. Expert Opin Drug Deliver, 2014, 11: 1939-1954

116 Das T, Pillai MRA. Options to meet the future global demand of radionuclides for radionuclide therapy. Nucl Med Biol, 2013, 40: 23-32

117 Kassis AI, Adelstein SJ. Radiobiologic principles in radionuclide therapy. J Nucl Med, 2005, 46: 4S-12S

118 Chen L, Luo Q, Shen Y, et al. Incremental value of 131I SPECT/ $\mathrm{CT}$ in the management of patients with differentiated thyroid carcinoma. J Nucl Med, 2008, 49: 1952-1957

119 Banerjee S, Pillai MRA, Knapp FFR. Lutetium-177 therapeutic radiopharmaceuticals: linking chemistry, radiochemistry, and practical applications. Chem Rev, 2015, 115: 2934-2974

120 Ferro-Flores G, Ocampo-García B, Santos-Cuevas C, et al. Theranostic radiopharmaceuticals based on gold nanoparticles labeled with ${ }^{177} \mathrm{Lu}$ and conjugated to peptides. Curr Radiopharm, 2015, 8: 150-159

121 Ait-Mohand S, Fournier P, Dumulon-Perreault V, et al. Evaluation of ${ }^{64} \mathrm{Cu}$-labeled bifunctional chelate-bombesin conjugates. Bioconjugate Chem, 2011, 22: 1729-1735

122 Chung US, Kim JH, Kim B, et al. Dendrimer porphyrin-coated gold nanoshells for the synergistic combination of photodynamic and photothermal therapy. Chem Commun, 2016, 52: 1258-1261

123 Zhang Y, Pang L, Ma C, et al. Small molecule-initiated lightactivated semiconducting polymer dots: an integrated nanoplatform for targeted photodynamic therapy and imaging of cancer cells. Anal Chem, 2014, 86: 3092-3099

124 Mohammadpour R, Safarian S, Buckway B, et al. Comparative endocytosis mechanisms and anticancer effect of HPMA copolymer- and PAMAM dendrimer-MTCP conjugates for photodynamic therapy. Macromol Biosci, 2017, 17: 1600333

125 Tao X, Yang YJ, Liu S, et al. Poly(amidoamine) dendrimer-grafted porous hollow silica nanoparticles for enhanced intracellular photodynamic therapy. Acta Biomater, 2013, 9: 6431-6438

126 Hutnick MA, Ahsanuddin S, Guan L, et al. PEGylated dendrimers as drug delivery vehicles for the photosensitizer silicon phthalocyanine Pc 4 for candidal infections. Biomacromolecules, 2017, 18: $379-385$

127 Rodriguez L, Vallecorsa P, Battah S, et al. Aminolevulinic acid dendrimers in photodynamic treatment of cancer and atheromatous disease. Photochem Photobiol Sci, 2015, 14: 1617-1627

128 Yang J, Zhang Q, Chang H, et al. Surface-engineered dendrimers in gene delivery. Chem Rev, 2015, 115: 5274-5300

129 Wang S, Wang F, Zhang Q, et al. A core-shell structured polyplex for efficient and non-toxic gene delivery. J Mater Chem B, 2017, 5: 5101-5108

130 Guan L, Huang S, Chen Z, et al. Low cytotoxicity fluorescent PAMAM dendrimer as gene carriers for monitoring the delivery of siRNA. J Nanopart Res, 2015, 17: 385

131 Shen W, Liu H, Ling-Hu Y, et al. Enhanced siRNA delivery of a cyclododecylated dendrimer compared to its linear derivative. J Mater Chem B, 2016, 4: 5654-5658

132 Liu C, Liu X, Rocchi P, et al. Arginine-terminated generation 4 PAMAM dendrimer as an effective nanovector for functional siRNA Delivery in vitro and in vivo. Bioconjugate Chem, 2014, 
25: $521-532$

133 Wang M, Liu H, Li L, et al. A fluorinated dendrimer achieves excellent gene transfection efficacy at extremely low nitrogen to phosphorus ratios. Nat Commun, 2014, 5: 3053

134 Kala S, Mak ASC, Liu X, et al. Combination of dendrimer-nanovector-mediated small interfering RNA delivery to target Akt with the clinical anticancer drug paclitaxel for effective and potent anticancer activity in treating ovarian cancer. J Med Chem, 2014, 57: 2634-2642

135 Chen H, Jia H, Tham HP, et al. Theranostic prodrug vesicles for imaging guided codelivery of camptothecin and siRNA in synergetic cancer therapy. ACS Appl Mater Interfaces, 2017, 9: 23536-23543

136 You JO, Guo P, Auguste DT. A drug-delivery vehicle combining the targeting and thermal ablation of HER2+ breast-cancer cells with triggered drug release. Angew Chem Int Ed, 2013, 52: 41414146

137 Ren F, Bhana S, Norman DD, et al. Gold nanorods carrying paclitaxel for photothermal-chemotherapy of cancer. Bioconjugate Chem, 2013, 24: 376-386

138 Song J, Pu L, Zhou J, et al. Biodegradable theranostic plasmonic vesicles of amphiphilic gold nanorods. ACS Nano, 2013, 7: 99479960

139 Song X, Liang C, Gong $\mathrm{H}$, et al. Photosensitizer-conjugated albumin-polypyrrole nanoparticles for imaging-guided in vivo photodynamic/photothermal therapy. Small, 2015, 11: 3932-3941

140 Taratula O, Schumann C, Duong T, et al. Dendrimer-encapsulated naphthalocyanine as a single agent-based theranostic nanoplatform for near-infrared fluorescence imaging and com- binatorial anticancer phototherapy. Nanoscale, 2015, 7: 38883902

141 Yang Z, Gao D, Cao Z, et al. Drug and gene co-delivery systems for cancer treatment. Biomater Sci, 2015, 3: 1035-1049

142 Zhang $\mathrm{XD}$, Wu D, Shen $\mathrm{X}$, et al. Size-dependent radiosensitization of PEG-coated gold nanoparticles for cancer radiation therapy. Biomaterials, 2012, 33: 6408-6419

143 Liang G, Jin X, Zhang S, et al. RGD peptide-modified fluorescent gold nanoclusters as highly efficient tumor-targeted radiotherapy sensitizers. Biomaterials, 2017, 144: 95-104

144 Wen S, Zhao Q, An X, et al. Multifunctional pegylated multiwalled carbon nanotubes for enhanced blood pool and tumor MR imaging. Adv Healthcare Mater, 2014, 3: 1568-1577

145 Mustafa R, Luo Y, Wu Y, et al. Dendrimer-functionalized laponite nanodisks as a platform for anticancer drug delivery. $\mathrm{Na}$ nomaterials, 2015, 5: 1716-1731

Acknowledgements This research is financially supported by the Fundamental Research Funds for the Central Universities (for Shi X, Xiong Z, and Shen M), the Science and Technology Commission of Shanghai Municipality (15520711400 and 17540712000), and the National Natural Science Foundation of China (81761148028 and 21773026).

Author contributions Xiong $\mathrm{Z}$ wrote the manuscript; Shen $\mathrm{M}$ and Shi $\mathrm{X}$ designed the outlines and carefully revised the manuscript.

Conflict of interest The authors declare that they have no conflict of interest. 

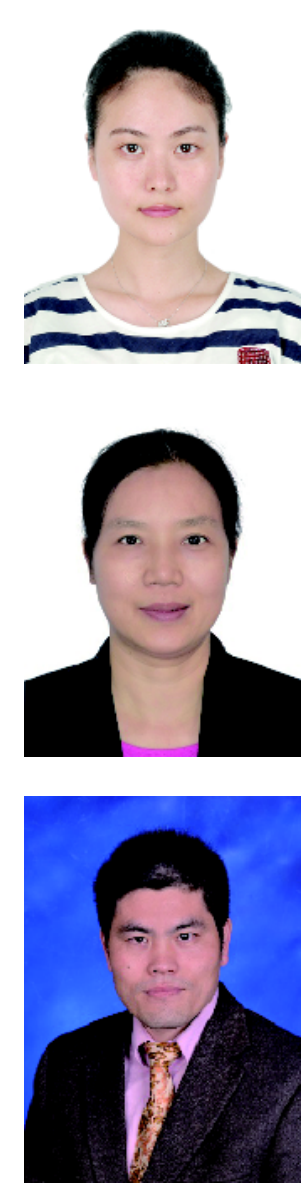

Zhijuan Xiong received her Bachelor's degree in biological engineering from Donghua University in 2014. Now she is a $\mathrm{PhD}$ student at Donghua University under the supervision of Prof. Xiangyang Shi. Her current research interests include the design of dendrimer-based systems for cancer diagnosis and therapy.
Mingwu Shen received her PhD degree in 2001 from Tsinghua University. Afterwards, she went to the University of Michigan, Ann Arbor as a visiting scholar and a research area specialist intermediate. She joined Donghua University in 2008 as an associate professor, and was promoted to be a full professor of biomedical engineering in 2018. Her current research interests include nanoparticle-based platforms for medical imaging and therapy applications, and the development of nanofiber-based technology for biomedical and environmental applications.
Xiangyang Shi obtained his PhD degree in 1998 from the Chinese Academy of Sciences. From 2002 to 2008, he was appointed as a research fellow, research associate II, research investigator, and research assistant professor in Michigan Nanotechnology Institute for Medicine and Biological Sciences, University of Michigan, Ann Arbor. In September 2008, he joined Donghua University as a full professor. His current research interests are focused on the development of organic/inorganic hybrid nanoplatforms and microfluidic platforms for sensing, imaging, and theranostic applications, in particular for precision cancer imaging and therapy.

\title{
基于树状大分子的癌症治疗策略: 最新进展和未来展望
}

\author{
熊智娟, 沈明武, 史向阳*
}

摘要 本文综述了一些基于树状大分子体系应用于癌症治疗的研究进展. 树状大分子拥有高度支化的三维球状结构、内部疏水空腔以及 多种表面功能基团, 因而可以作为药物和纳米颗粒的载体或者稳定剂. 装载了治疗试剂(如药物、siRNA或者纳米颗粒)的纳米平台可进一 步被修饰而获得靶向特异性、抗污性能和良好的生物相容性. 本文详细介绍了树状大分子表面修饰并作为多功能平台应用于对癌症的不 同治疗手段的进展, 包括: 化疗、放疗、光热治疗、光动力治疗、基因治疗以及联合治疗. 